\title{
Nomenclatura em Polímeros
}

A tradução da palavra nomenclatura, não somente como vocabulário de nomes ${ }^{[1]}$ mas, principalmente como conjunto de termos peculiares a uma arte ou ciência $^{[1]}$, torna-se ainda mais significativa se for considerada a importância da comunicação para o desenvolvimento das ciências, especialmente no atual contexto de rápido desenvolvimento de novas tecnologias. Geralmente concebidas em meio acadêmico, com características de linguagem e divulgação próprias, as novas tecnologias somente encontram mercado após a tradução realizada pelos profissionais de formação tecnológica, encarregados do desenvolvimento de produtos e processos cujo sucesso depende da boa comunicação dos profissionais destes dois setores, apoiada em uma nomenclatura racional.

$\mathrm{O}$ rápido crescimento das pesquisas na área de Polímeros em nosso país, especialmente nos últimos quinze anos, é resultado da maturidade da comunidade de pesquisadores que se dedicam ao desenvolvimento desta ciência. Como um dos frutos desta intensa atividade foi criada a Associação Brasileira de Polímeros e, como conseqüência desta, foram criados esta revista e o Congresso Brasileiro de Polímeros. Estas duas últimas iniciativas estimularam e deram maior divulgação a textos e artigos científicos em língua portuguesa no Brasil. Antes deste período a literatura de qualidade científica em Polímeros, redigida em nosso idioma, estava restrita às dissertações e te- ses universitárias ${ }^{[2]}$ e aos poucos livros escritos por pesquisadores brasileiros ${ }^{[3,4,5]}$ ou traduzidos do idioma inglês ${ }^{[6]}$.

A intensa divulgação científica em língua inglesa e a existência de nomenclatura já estabelecida neste idioma vêm retardando o estabelecimento de uma nomenclatura para a área de Polímeros em língua portuguesa. A ausência de um vocabulário próprio e comum a todos tem provocado várias situações que dificultam a comunicação entre os pesquisadores do meio acadêmico e entre estes e os que se dedicam ao setor produtivo. Na área industrial, a ausência de uma nomenclatura reconhecida em Polímeros é particularmente danosa quando se considera atividades básicas como controle de estoque, transporte de produtos, armazenagem, tributação de produtos, entre outras. Ainda nesta área, merece destaque a comunicação por meio de boletins e relatórios técnicos, bem como a divulgação de pesquisas tecnológicas por meio de revistas especializadas.

Além da área de produtos, a nomenclatura se faz extremamente necessária para a caracterização de materiais poliméricos, relativamente quanto a propriedades químicas e físicas, bem como diferentes comportamentos observados em modernas técnicas analíticas que surgem a todo momento.

A nomenclatura em Polímeros adotada de forma não oficial em nosso país resulta de traduções, algumas vezes literais, de termos já consagrados ou estabelecidos no idioma inglês. Situação às vezes agravada pela inexistência de palavra correspondente em nosso idioma.

O Comitê Editorial e o Corpo de Assessores desta revista têm encontrado dificuldades ao analisar textos que utilizam terminologias diferentes para designar o mesmo conceito, como por exemplo: enxertia ou graftização; massa molar ou peso molecular; Calorimetria Diferencial de Varredura ou Calorimetria Exploratória Diferencial e blendas ou misturas.

Esta situação está próxima de chegar a um bom termo com a esperada publicação, em língua portuguesa, do original em inglês "Compendium of Macromolecular Nomenclature", da IUPAC, trabalho este realizado por uma equipe de professores do IMA/UFRJ, sob a coordenação da Professora Cristina T. Andrade.

Aguardando essa publicação, o Comitê Editorial de Polímeros: Ciência e Tecnologia realizou uma consulta preliminar junto a vários pesquisadores que atuam na área de Polímeros no país, visando levantar os pontos mais polêmicos sobre o assunto. As opiniões apresentadas a seguir correspondem a um resumo condensado das respostas recebidas.

Analisando a situação atual do uso de termos técnicos e científicos na área de Polímeros no Brasil, todos os pesquisadores consultados afirmaram que os problemas são numerosos, conseqüência do progresso acelerado que ocorre na área de Polímeros em nível mundial, divulgado quase que exclusivamente em língua inglesa. A necessidade de tradução de palavras ainda não 
existentes em língua portuguesa; ou o mal aproveitamento das que existem, leva a um "aportuguesamento" arbitrário destes novos termos. Dentre as respostas obtidas, pode-se perceber claramente um chamamento à responsabilidade dos pesquisadores brasileiros no desenvolvimento de uma terminologia específica para esta área de conhecimento.

Todos os pesquisadores foram unânimes em afirmar a necessidade de normatização de termos técnicos e científicos empregados na área de Polímeros. O principal aspecto a ser trabalhado seria, além de seguir as normas internacionais da IUPAC, definir critérios para a criação de palavras em língua portuguesa, nos casos em que isto for necessário.

Além das várias propostas apresentadas a seguir, várias respostas destacaram as iniciativas já realizadas ou em realização por pesquisadores brasileiros, dentre as quais destacamos a publicação preparada pelo Instituto Brasileiro de Petróleo ${ }^{[7]}$, o artigo do Professor José Augusto M. Agnelli, publicado em Boletim da $\mathrm{ABPol}^{[8]} \mathrm{e}$ o trabalho coordenado pela Professora Cristina T. Andrade, anteriormente citado. Estas iniciativas deveriam ser consultadas em uma primeira fase do processo de normatização e, eventualmente, nortear este processo. A viabilização sugerida pelos pesquisadores consultados se daria pela criação de uma terminologia própria que deveria, preferencialmente, ser calcada em idéias simples, autoexplicativas, baseadas no conhecimento dos fenômenos, dos materiais, das operações ou dos processos. Somente se considerações deste tipo não levassem a um termo adequado (o que ocorrerá quando estivermos lidando com algo completamente novo), poderemos, eventualmente, adotar ou aportuguesar correspondentes termos estrangeiros.
Este trabalho deveria ser realizado por pesquisadores da área (científica e tecnológica) com recursos financeiros obtidos junto a organismos de apoio a pesquisa. A participação da comunidade deveria ser fomentada por meio de debates e apresentação de trabalhos em Congressos. Além disso, artigos com divulgação das discussões poderiam ser publicados em revistas especializadas.

Para uma maior facilidade de implantação, a implementação de uma nomenclatura em Polímeros deveria contar com a participação de vários setores organizados, tais como Universidades, Centros de P\&D, Escolas Técnicas, Associações Científicas e Profissionais (ABPol, ABQ, SBQ, ABIQUIM, PLASTIVIDA, ABTB, ABIARB, ASPLAR, ABRE, CETEA), Empresas atuantes no setor de Polímeros, ABNT e INMETRO. Segundo os pesquisadores consultados, a iniciativa deste processo de estabelecimento de nomenclatura deveria ficar com a comunidade universitária, por meio de instituições organizadas, dentre as quais foram citadas a própria ABPol e o IMA/ UFRJ.

Os pesquisadores consultados concordam, em sua maioria, na adoção da nomenclatura da IUPAC, em língua inglesa, como base para o desenvolvimento da Nomenclatura Brasileira de Polímeros. Os pontos que deveriam ser abordados em uma primeira fase contemplam nomes e siglas de polímeros e termos técnicos relacionados à polimerização e ao processamento. Em seguida deveriam ser abordados termos próprios de caracterização e propriedades (físicas, químicas e físico-químicas) de materiais poliméricos.

Como sugestões finais, foi destacada a necessidade de compatibilização com a nomenclatura de outras áreas do conhecimento, já existente em nosso idioma e a oficialização desta futura Nomenclatura Brasileira de Polímeros por meio de órgãos como a ABNT.

O principal resultado deste levantamento de opiniões foi a unanimidade de todos os pesquisadores quanto à necessidade premente de uma Nomenclatura para a área de Polímeros. Os trabalhos já iniciados e o crescimento desta importante área de pesquisa em nosso país deverão culminar, em futuro que esperamos seja breve, com a desejada e necessária Nomenclatura Brasileira de Polímeros.

1. Bueno, F. da S. - "Dicionário Escolar da Língua Portuguesa”, $11^{a}$ edição, FAE, Rio de Janeiro (1985).

2. Destaque especial deve ser reconhecido ao pioneiro trabalho do antigo Instituto de Macromoléculas da Universidade Federal do Rio de Janeiro - IMA, hoje Instituto de Macromoléculas Professora Eloisa Mano.

3. Mano, E. B. - "Introdução a Polímeros", Editora Edgard Blücher Ltda., São Paulo (1985).

4. Mano, E. B. - "Polímeros como Materiais de Engenharia”, Editora Edgard Blücher Ltda., São Paulo (1991).

5. Blass, A. - "Processamento de Polímeros", Editora da Universidade Federal de Santa Catarina, Florianópolis (1985).

6. Alfrey, T. \& Gurnee, F. (Tradução Júlio Buschinelli) - "Polímeros Orgânicos", Editora Edgard Blücher Ltda., São Paulo (1971).

7. Mano E. B. e colaboradores, "Terminologia de Polímeros: Inglês - Português", Instituto Brasileiro de Petróleo, Rio de Janeiro (1988), 72 pp.

8. Agnelli, J. A. M. - Boletim da ABPol, 1(4), p.31-61 (1990).

Matéria elaborada pelo Prof. Dr. Antonio Aprigio S. Curvelo do Instituto de Química da USP São Carlos e pelo Prof. Dr. José Augusto M. Agnelli do Departamento de Engenharia de Materiais da UFSCar. 